\title{
Internal multiband PIFA antenna for GPS/DCS/PCS/ UMTS/WLAN operation in the mobile device
}

\author{
Mohammad Akbari ${ }^{\mathrm{a})}$, Changiz Ghobadi, and Javad Nourinia \\ Department of Electronics of Communication, University of Urmia, \\ Urmia 57153, Iran \\ a)St_m.akbari@mail.urmia.ac.ir
}

\begin{abstract}
This letter presents a wideband antenna of the modified planar inverted-F antenna (PIFA), which covers GPS, DCS, PCS, UMTS, and WLAN band. The proposed antenna mainly comprises four resonance frequencies of rectangular patch, two strips and Ushaped slot, which fed by a $50 \Omega$ coaxial line, occupies a volume of $21 \times 27 \times 4 \mathrm{~mm}^{3}$. The mobile phone considered in this study has a system ground plane of size $32 \times 60 \times 0.2 \mathrm{~mm}^{3}$. Measured results show that the proposed antenna provides enough bandwidth to cover five bands for return loss less than $-6 \mathrm{~dB}(\mathrm{VSWR}<3)$. The simulated return loss is compared with measured return loss, which shows a good agreement between them.
\end{abstract}

Keywords: planar inverted-F antenna (PIFA), mobile device

Classification: Microwave and millimeter wave devices, circuits, and systems

\section{References}

[1] S. T. Fang, S. H. Yeh, and K. L. Wong, "Planar inverted-F antennas for GSM/DCS mobile phones and dual ISM-band applications," IEEE Antennas Propag. Society Int. Symp. 2002, vol. 4, pp. 524-527, 2002.

[2] S. Tarvas and A. Isohatala, "An internal dual-band mobile phone antenna," IEEE Antennas Propag. Society Int. Symp. 2000, vol. 1, pp. 266$269,2000$.

[3] K. Ogawa, T. Uwano, and M. Takahashi, "A shoulder-mounted planar antenna for mobile radio applications," IEEE Trans. Veh. Technol., vol. 49, no. 3, pp. 1041-1044, May 2000.

[4] C. R. Rowell and R. D. Murch, "A compact PIFA suitable for dual frequency 900/1800-MHz operation," IEEE Trans. Antennas Propag., vol. 46, no. 4, pp. 596-598, 1998.

[5] H. Park, K. Chung, and J. Choi, "Design of planar inverted-F antenna with very wide impedance bandwidth," IEEE Microw. Wireless Compon. Lett., vol. 16, no. 3, pp. 113-115, March 2006. 


\section{Introduction}

Due to the rapid development and widespread usage of various communication systems, the antenna is required to operate at five or more frequency bands. It is desirable for a single handset to access the several additional services such as voice, data and video at anytime and anyplace. Therefore, more and more attention has been paid to designing a new internal antenna, which has higher efficiency, moderate bandwidth, low profile, low cost and the fact that it is lightweight and less prone to breakage compared to conventional external monopole or helical antenna. An attractive candidate for such an antenna is a planar inverted-F antenna (PIFA) $[1,2,3,4]$. However, due to the high Q, a basic PIFA element has narrow bandwidth of about 4 to $12 \%$ for $-10 \mathrm{~dB}$ return loss requirement $[4,5]$. It is possible to design PIFAbased multiband internal antennas by considering variants of PIFA structure in combination with other broad banding techniques. The proposed PIFA is made up of a ground plane, radiating patch, two strips, U-shaped slot, and a shorting pin which results in a quarter-wavelength resonator. In other words, a size reduction of $50 \%$ in length can be obtained in comparison to the conventional half-wavelength radiator. This antenna satisfies a $-6 \mathrm{~dB}$ return loss requirement to cover the Global Positioning System, $1550-1610 \mathrm{MHz}$ (GPS1574.5), Digital Communication System, 1710-1880 MHz (DCS1800), Personal Communication System, 1850-1990 MHz (PCS1900), Universal Mobile Telecommunication System, 1920-2170 MHz (UMTS), and Wireless Local Area Network, 2400-2483.5 MHz (WLAN) services at the same time. In the following sections, a planar inverted-F antenna having wide impedance bandwidth is designed and its return loss and radiation pattern characteristics are measured.

\section{Antenna configuration}

The geometry and dimensions of the radiating elements and the proposed PIFA are shown in Fig. 1. The modified five-band antenna that was developed within a $27 \times 21 \times 4 \mathrm{~mm}^{3}$ (volume of $2.27 \mathrm{~cm}^{3}$ ) area is placed at the center-top position of the ground copper measuring $32 \times 60 \times 0.2 \mathrm{~mm}^{3}$. The antenna is made of FR4 $\left(\varepsilon_{r}=4.4\right)$ substrate. It is fed by a $50 \Omega$ coaxial cable and has four radiating elements on the top face. The feed point is placed between the radiator patch and the two strips. The antenna design is started with a conventional dual band PIFA element with single feed and a shorting pin. The height of the radiating patch, the width of the shorting pin, and the size of the ground plane has the greatest influence on the bandwidth and the resonant frequency of the PIFA. In general, the bandwidth broadens with increasing the height of the radiating patch.

\section{Results and discussion}

The simulated and measured return losses of the antenna are shown in Fig. 2. Ansoft high frequency structure simulator (HFSS) is used for full wave analysis of the antenna structure. Perfect electric conductor (PEC) is assumed 


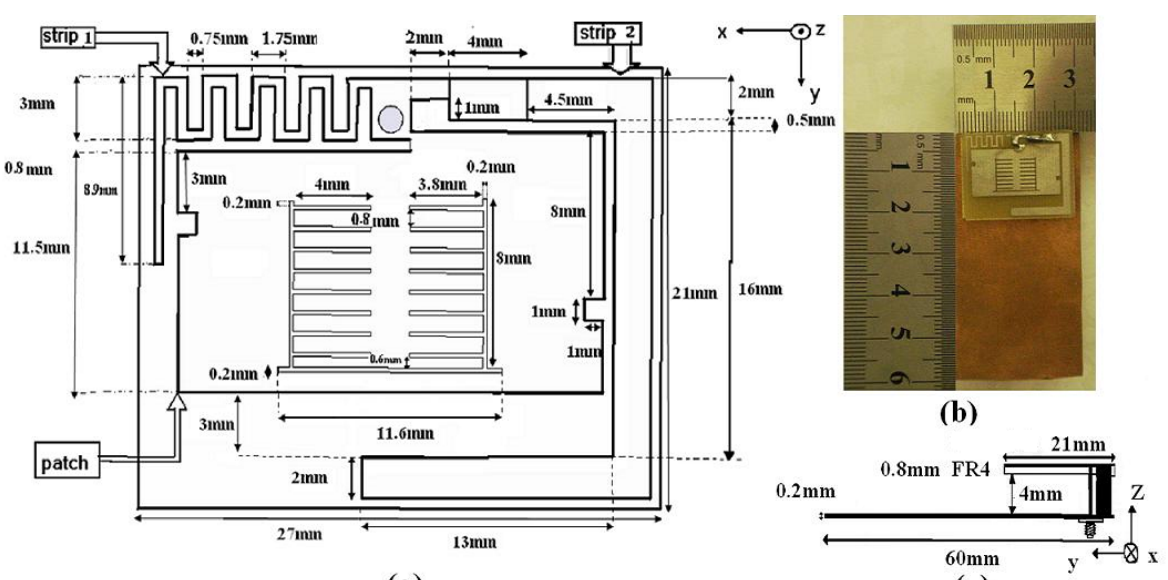

(a)

(c)

Fig. 1. Dimension and Configuration of the proposed antenna (a) Front view (b) photo of the implemented antenna and (c) Side view.

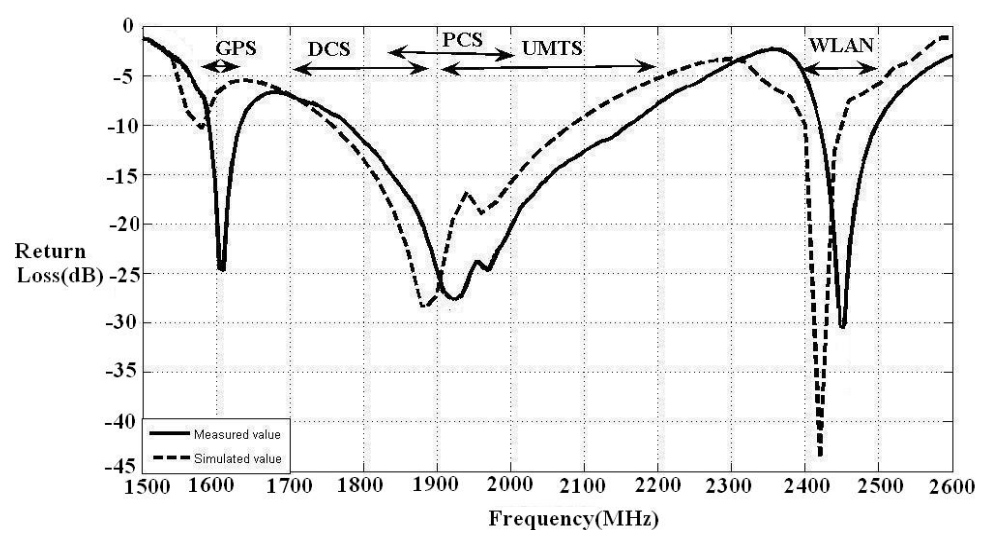

Fig. 2. Simulated and measured return loss for the proposed antenna.

in the simulation setup and an ideal port is used to excite the antenna structure. Material losses have been ignored in the simulations. Measured return loss for the proposed antenna was tested by the E8362B network analyzer. The optimized height of the proposed antenna is $4 \mathrm{~mm}$, which is suitable for practical mobile handsets. The total effective length and width of the strip 2 from shorting pin is about $37.5 \mathrm{~mm}$ and $2 \mathrm{~mm}$ respectively. At frequency of $1574.5 \mathrm{MHz}$, this total length results in an impedance bandwidth covering the GPS band for the proposed antenna. On the other hand, the effective resonant length and width of the strip 1 from feed point is about $40 \mathrm{~mm}$ and $0.5 \mathrm{~mm}$, respectively. Quarter-wavelength long patch and strip 1 resonator are directly connected to the feed point. It results in a wide band impedance matching at $1900 \mathrm{MHz}$ and $1950 \mathrm{MHz}$ covering most of the wireless communication bands starting from DCS to UMTS band for the proposed antenna. In order to get resonance at $2.44 \mathrm{GHz}$ and to cover UMTS band, in the designed antenna, the U-shaped slot is used in the radiating patch, which these slots effectively act to increase electrical length of the PIFA and reduce

(C) IEICE 2009

DOI: 10.1587/elex.6.1752 Received October 31, 2009 Accepted November 17, 2009 Published December 25, 2009 
Table I. Measured radiation efficiency $(\% \eta)$ and efficiency of the proposed antenna.

\begin{tabular}{|c|c|c|c|c|c|}
\hline Frequency (GHz) & 1.575 & 1.790 & 1.920 & 2.045 & 2.440 \\
\hline Radiation Efficiency & 70 & 90 & 92 & 89 & 62 \\
\hline Efficiency & 62 & 85 & 75 & 66 & 60 \\
\hline
\end{tabular}
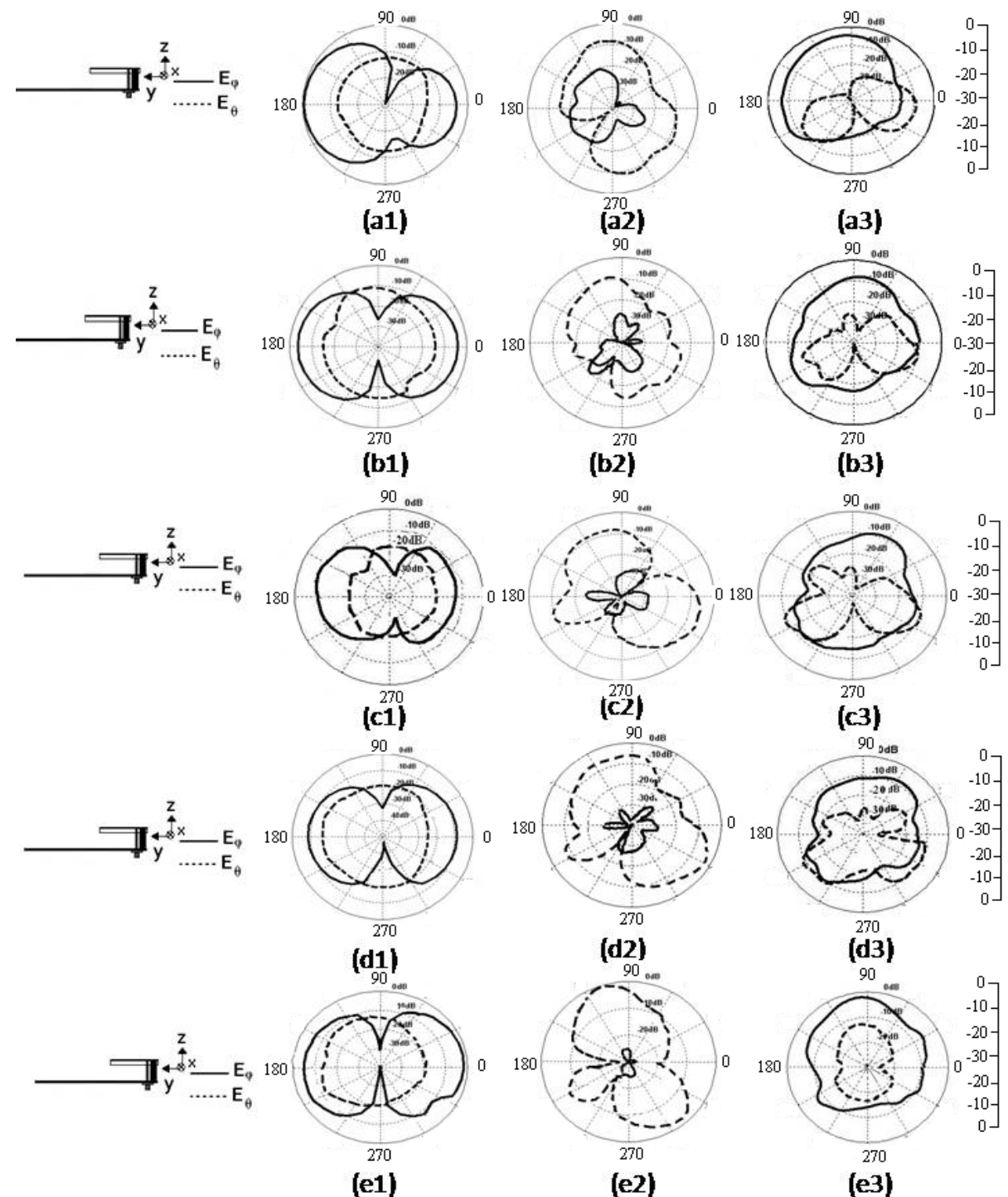

Fig. 3. Measured radiation patterns for the proposed antenna at (a) $1575 \mathrm{MHz}$, (b) $1795 \mathrm{MHz}$, (c) $1920 \mathrm{MHz}$, (d) $2045 \mathrm{MHz}$, (e) $2442 \mathrm{MHz}$ and (1) x-y plane; (2) y-z plane; (3) x-z plane.

the antenna size. To improve the bandwidth at UMTS band, U-shaped slot is located at the center of the patch and is not located at edges of the patch. To achieve the best matching and enhance bandwidth performance, not only the length and height of a rectangular patch but also the length and width of the two strips are optimized. The measured radiation efficiency $(\% \eta)$ and efficiency of the proposed antenna at different frequency bands are given in Table I. The measured co-polarized and cross-polarized radiation patterns 
at $1.575 \mathrm{GHz}, 1.795 \mathrm{GHz}, 1.92 \mathrm{GHz}, 2.045 \mathrm{GHz}$, and $2.445 \mathrm{GHz}$ are plotted in Fig. 3.

\section{Conclusion}

In this paper, a novel multi-band PIFA has been designed and manufactured to cover the GPS, DCS, PCS, UMTS, and WLAN bands at the same time. The width of the two strips and patch, ground plane length, width of the shorting pin, and height between the main patch and the ground plane of the proposed antenna play important roles in achieving an increased impedance bandwidth and reduced size antenna. The measured results show that the return loss characteristics are satisfied in all five frequency bands and reasonably good radiation characteristics are candidates for hand-held application. Considering small size, wide bandwidth, low cost, and easy design capability, the proposed antenna is very suitable for modern compact mobile phones. Measured and simulated return loss and radiation patterns are in agreement.

\section{Acknowledgments}

The authors are thankful to Iran Telecommunication Research Center (ITRC) for its financial support and also the Antenna Lab of the Khaje Nasir Toosi University of Technology (Tehran, Iran) where the proposed antenna has been tested. 